\title{
Neonatal circumcision: the controversy rages on
}

\author{
Suzanne J Farley
}

In this issue, the second of a pair of pro/con Viewpoints addressing the clinical utility of circumcising male infants is published. Robert Van Howe, a Clinical Professor of Pediatrics, rebuts the points raised by Paul Austin in the January issue of the journal. Van Howe asserts that "as a public health measure, newborn circumcision in the US has failed to show a benefit in protecting against cervical cancer, penile cancer, STIs, and HIV." By contrast, it is Austin's view that "an abundance of data and emerging evidence supports the public health benefits associated with circumcision."

The divergence in the opinions of these two authors is indicative of widespread confusion among practitioners about how best to advise parents who are considering circumcision for their sons. Guidance from the American Academy of Pediatrics is of little practical value to clinicians negotiating the minefield of personal beliefs, cultural influences and conflicting data that affect the circumcision decision. The most recent AAP policy statement, published in 1999, concluded that "there are potential benefits and risks, [but] insufficient data to recommend routine neonatal circumcision." The upshot is that parents should determine what is in the 'best interests' of their child.

Can two people truly determine what is in the 'best interests' of another? How can the future opinions of a newborn be predicted, even by the child's parents? Does 'best interests' in this context, therefore, essentially boil down to the preferences of the parents?

Of course, these questions can be asked of consent for any pediatric procedure. Circumcision cannot, however, be considered a 'treatment' in the same way as, for example, surgical correction of a life-threatening injury. Indeed, the AAP concludes that "[circumcision] is usually not essential to the child's well being." In the absence of irrefutable, highquality data, weighing the immediate risk of

\section{"Very few adult men [in developed countries] choose to be circumcised." Given the available data, would you?}

SJ Farley is Deputy Editor of Nature Clinical Practice Urology.

\section{Competing interests}

The author declared no competing interests.

www.nature.com/clinicalpractice doi:10.1038/ncpuro1300 complications against the potential benefits of the procedure is so fraught that the decision is often based solely on personal belief-both of the child's parents and, indirectly, of their medical advisors.

If parents elect to have their son circumcised, who should pay? In 16 US states, Medicaid no longer covers the cost (estimated to be \$250-300) of nonessential neonatal circumcision. Circumcision rates are markedly lower in these regions (Leibowitz AA et al. [2009] Am J Public Health 99: 138-145). If a clinical benefit of 'preventive' circumcision is proved in the future, this fiscal discrimination will have potentially compromised the health of men whose parents could not afford to have them circumcised as children, as well as increasing the cost to the state of managing conditions that might have been prevented.

The most compelling evidence for the preventive value of circumcision is that drawn from three randomized controlled trials conducted recently in Africa. On the basis of these studies, the $\mathrm{WHO}$ and the UN have recommended that circumcision be incorporated into HIV prevention programs. As Austin points out, "in the future this could be a public health benefit that can be transferred to the US and other industrialized countries" (Austin PF [2009] Nat Clin Pract Urol 6: 16-17).

The African studies enrolled adults; it is problematic, therefore, to extrapolate the results to neonates. Promotion of noninvasive HIV prevention practices (e.g. condom use) has been more successful in controlling the spread of infection in developed nations, and could negate any benefit of pre-emptive circumcision. Furthermore-and perhaps most importantly - the men who participated in the African trials were able to consent to the procedure themselves. As Van Howe points out on pages 74-75 "very few adult men [in developed countries] choose to be circumcised." Given the available data, would you? 